\section{Our Inner Conflicts}

A Constructive Theory of Neurosis. By Dr. Karen Horney. Pp. 250. (London: Kegan Paul and Co., Ltd., 1946.) 10s. $6 d$. net.

NANY attempts have been made to modify the 1 original Freudian technique and theories regarding the origin and treatment of neurosis. This book describes the variations which Dr. Horney has developed and gives an outline of her views on psychology, which are interesting and coherent. The first thing which strikes the reader is that the analyses she records are not transference analyses in the Freudian sense at all and, in fact, the word 'transference' does not appear in the index. She does not believe, with Freud, that neuroses are caused by some distortion of the instinct but that they are the product of abnormal personality. She thinks that anxiety is produced by isolation, for example, and not by castration fears or birth trauma; that obsessions are due to disturbed personal relationships and not to repressed sadistic impulses, and so on. Her views on personality are individual also. She believes that there are three types: (1) compliant, (2) aggressive, (3) detached. They are really devices to deal with the patient's basic anxiety. This anxiety is also avoided by idealization of the ego, so that the patient is able to see himself as more perfect than he really is. The neurotic conflicts, she thinks, often lead to diversion of energy from useful channels, so that there is an impoverishment and inertia, the final stages of which are an all-pervading feeling of hopelessness.

Dr. Horney's psychology is half-way between that of Freud and Adler. She has a moralistic approach and her analytical technique is purely interpretative, but her views are based on clinical work and will be of interest to the psychotherapist, particularly those with Adlerian inclinations. CLIFFORD ALLEN

\section{Practical Physiological Chemistry}

By Dr. Philip B. Hawk, Dr. Bernard L. Oser and Dr. William H. Summerson. Twelfth edition. Pp. xiv + 1323. (London: J. and A. Churchill, Ltd., 1947.) $50 s$.

T HE rapidity with which advances are made in our knowledge of biochemistry and the fields of study with which it shares common ground makes the frequent revision of text-books dealing with these subjects a real necessity. It is ten years since the publication of the eleventh edition of Hawk's "Practical Physiological Chemistry", so that the appearance of a new edition is both timely and welcome. In the forty years since its first publication, this text-book has achieved a position which is probably unique. It is of value to teachers, research workers and routine analysts alike, the treatment of most aspects of the subject being both theoretical and practical and the scope of the experimental sections the widest possible.

The extensive additions and revision which have now been made will undoubtedly greatly increase its value to all its users. The changes embodied in the new edition are too many to mention in detail; but the following are some of the more considerable ones. A new chapter has been added, dealing with antibiotics, including penicillin, gramicidin, tyrocidine and streptomycin, and with metabolic antagonists, including analogues of vitamins and amino-acids. The chapter on enzymes has a new section concerned with cellular respiration, in which the Warburg manometric technique is described. The section on colorimetry has been extended to include a detailed account of various types of photometric technique. Other recently developed experimental techniques which are now discussed are microbiological assay of vitamins and amino-acids, polarography, use of isotopes and electrophoresis.

The chapters on hormones and vitamins have been extended to cover the enormous developments which have taken place since 1937, considerable attention being paid to the estimation of vitamins : it is in these sections more than in any others that the extent of the progress made in the last decade is apparent. Several new appendixes have been added, including one dealing with the analysis of variance, and a new feature is the inclusion in each chapter of a bibliography of relevant recent publications. These additions and many others have necessitated a considerable increase in the size of the book, which is, however, still very clearly printed and well indexed. In summary, it may be said that the new edition should ensure the maintenance by this book of its well-deserved popularity.

\section{My Caves}

By Norbert Casteret. 'Translated by R. L. G. Irving. Pp. $x i+172+16$ plates. (London: J. M. Dent and Sons, Ltd., 1947.) 15s. net.

7 HIS is a book which the general reader will enjoy and find exciting as well as informative. M. Casteret, well known already for his earlier study, "Ten Years under the Earth", has written it "not . . as a technician, but as a dilettante", and in taking the reader "on a pleasure outing in the cave. country" he writes vividly of his experiences in potholing, in "reptation" and in the patient observation of the habits of bats. He devotes a chapter to each of these activities, and deals also with the purpose of spelæology and the equipment needed for its pursuit. He displays, as well as considerable courage, a sense of humour and an æesthetic, indeed almost mystical, appreciation of the wonders of the under. world. He writes with respect of the pioneers of cave exploration and marvels at the Palæolithic troglodytes. Enough is said of the value of spelæology to the geophysicist, the botanist and the hydroelectric engineer to show that it is more than a sport, though the appetite for scientific knowledge is no more than whetted.

The photographs, some taken underground by $M$. Casteret himself, are interesting and varied, and the translation is good and reads quite naturally, although English equivalents for some French technical terms had to be devised.

\section{An Introduction to Filmstrips}

By H. R. and I. W. Dance. Pp. 36. (London: George G. Harrap and Co., Ltd., 1948.) 2s. 6d. net.

TH.IS pamphlet contains a deal of common sense 1 in a short space. Written with the needs of the classroom teacher firmly in mind, the technical processes of filmstrip production, the pros and cons of different types of apparatus and the basic principles involved in the use of this form of teaching aid are dealt with succinctly, lucidly and objectively. The line drawings and half-tone illustrations which accompany the text where necessary are admirably chosen for their purpose. On the most controversial point dealt with, the choice of frame size, the authors present a strongly argued case in favour of doubleframe strip (24 mm. $\times 36 \mathrm{~mm}$.) for general purposes, 